\title{
Rapid tranquillisation: are we getting it right?
}

\author{
Laura Mannion, Darina Sloan and Louise Connolly
}

\begin{abstract}
Trainees in psychiatry frequently employ rapid tranquillisation (RT) measures. In this study we surveyed trainees as to RT regimes used. We found that a variety of drugs were chosen. On 45 (46\%) occasions one drug was used, on 53 (54\%) a combination. Drugs were administered in intramuscular form in $88(90 \%)$ incidents. Zuclopenthixol acetate was prescribed on a fotal of 45 (46\%) occasions. In 38 (39\%) incidents the trainee used a high-dose regime. The literature regarding RT indicates inconsistency in practice. We address the reasons for this and make suggestions as to possible improvement in practice.
\end{abstract}

Junior doctors, when confronted with patient violence, must make swift decisions with regard to management. Frequently this management involves the use of rapid tranquillisation (RT). This has been defined as the administration of varying amounts of antipsychotic medication over brief intervals of time to control agitated and threatening patients (Dubin, 1989).

\section{The study}

A questionnaire was circulated to trainees participating in three training schemes. Respondents were questioned as to their use of RT measures in the previous six months. Data collected included the type, dosage, and route of administration of medication.

\section{Findings}

Fifty-five questionnaires were returned (response rate $79.7 \%)$. Forty-six $(83.6 \%)$ respondents reported experiencing at least one violent incident, with 108 separate incidents reported. On 98 occasions $(90.7 \%)$, trainees prescribed medication to control behavioural disturbance. In 45 (46\%) incidents one drug was used, with two drugs prescribed on $43(44 \%)$ occasions, while three drugs were prescribed on $10(10 \%)$ occasions. On $88(90 \%)$ occasions, intramuscular (i.m.) medication was administered. Zuclopenthixol acetate was prescribed in a total of 45 incidents, alone on 25 occasions, and in combination on 20 occasions. Benzodiazepines were prescribed on 40 occasions $(41 \%)$, in combina- tion in the majority of instances (34). Chlorpromazine and haloperidol were both prescribed on a total of 26 occasions (26.5\%). Further information is given in Table 1 .

Examination of drug combinations and dosages revealed that on $38(39 \%)$ occasions the trainee prescribed medication that could be regarded as being within a high-dose range compared with British National Formulary (BNF) (1995) recommendations. For example, the BNF recommendations regarding the maximum single i.m. dose of chlorpromazine was exceeded on 25 occasions. Other examples of high-dose regimes include the use of a combination of haloperidol $15 \mathrm{mg}$, droperidol $10 \mathrm{mg}$ and lorazepam $4 \mathrm{mg}$; and a combination of haloperidol $20 \mathrm{mg}$, lorazepam $4 \mathrm{mg}$ and zuclopenthixol acetate $100 \mathrm{mg}$, all given i.m. Further information as to high-dose prescribing is given in Table 2.

Trainees prescribed more than one antipsychotic on $24(24 \%)$ occasions. On 18 (18\%) occasions a butyrophenone/benzodiazepine combination was used, and in six incidents a phenothiazine/benzodiazepine combination.

When questioned as to the existence of a policy for RT in their workplace, 53 trainees (96.3\%) replied that no such policy was in place.

\section{Comment}

We found that $39 \%$ of trainees surveyed prescribed drugs within a high-dose range. This trend is a cause for concern, especially in light of the Royal College of Psychiatrists' Consensus Statement on the use of high-dose antipsychotic medication (Thompson, 1994), which states that exceeding the recommended dose range is likely to risk higher levels of side-effects, thereby exceeding the acceptable risk-benefit ratio. Furthermore it states that a trainee psychiatrist is not considered sufficiently qualified to exceed the recommended BNF upper dose limit. In this survey it was difficult to establish whether trainees were at all times acting under specialist supervision, but as the majority of incidents occurred in an on-call or emergency situation it may be that this was not the case. 
Table 1. Details of rapid tranquillisation episodes reported by trainees

\begin{tabular}{|c|c|c|c|c|c|}
\hline Drug & $\begin{array}{l}\text { Monothercpy } \\
\text { incidents }\end{array}$ & $\begin{array}{l}\text { Polythercipy } \\
\text { incidents }\end{array}$ & $\begin{array}{l}\text { Total } \\
n(\%)\end{array}$ & $\begin{array}{l}\text { Dose range } \\
\text { (mg) }\end{array}$ & Administration \\
\hline $\begin{array}{l}\text { Zuclopenthixol a. } \\
\text { Chlorpromazine } \\
\text { Haloperidol } \\
\text { Droperidol } \\
\text { Lorazepam } \\
\text { Diazepam } \\
\text { Chlordiazepoxide } \\
\text { Sodium } \\
\text { amytal (amylobarbitone) }\end{array}$ & $\begin{array}{r}25 \\
6 \\
3 \\
5 \\
2 \\
2 \\
2 \\
0\end{array}$ & $\begin{array}{r}20 \\
20 \\
23 \\
13 \\
30 \\
4 \\
0 \\
2\end{array}$ & $\begin{array}{l}45(45.9 \%) \\
26(26.5 \%) \\
26(26.5 \%) \\
18(18.3 \%) \\
32(32.6 \%) \\
6(6.1 \%) \\
2(2 \%) \\
2(2 \%)\end{array}$ & $\begin{array}{l}100-150 \\
100-200 \\
5-20 \\
10-20 \\
2-4 \\
5-10 \\
20 \\
200\end{array}$ & $\begin{array}{l}\text { I.m. } \\
\text { p.o.; i.m. } \\
\text { p.o.; i.m.; i.v. } \\
\text { i.m. } \\
\text { p.o.; i.m.; i.v. } \\
\text { i.m.; i.v. } \\
\text { p.o. } \\
\text { i.m. }\end{array}$ \\
\hline
\end{tabular}

i.m.=intramuscularly; i.v.=intravenously; p.o.=per os (by mouth).

Trainees prescribed more than one antipsychotic on $24(24.4 \%)$ occasions. The BNF warns against this, as it may constitute a hazard and does not appear to minimise side-effects. It would appear that trainees do not have a full knowledge of the equivalent doses of antipsychotics, and the consequent risk of exceeding dose recommendations when combining drugs. Medication was administered intramuscularly on $\mathbf{8 8}$ (90\%) occasions. On 55 (56\%) occasions this involved an antipsychotic other than zuclopenthixol acetate. The risks of parenteral administration are recognised, with higher blood levels known to be achieved via this route. Our results suggest that some trainees prescribe i.m. doses of antipsychotics as they would oral medication. without decreasing the dose accordingly.

The combination of a butyrophenone and a benzodiazepine has been recommended for RT practice (Dubin, 1989; Thompson, 1994). This combination was prescribed on $18(18 \%)$ occasions only. Zuclopenthixol acetate was far more frequently prescribed. The Royal College agrees that zuclopenthixol is useful in these situations, but caution has been expressed with regard to the hazards of administering an antipsychotic with a long half-life to previously untreated patients. Zuclopenthixol acetate was used fre- quently in combination with other drugs. Its use in combination with another antipsychotic may, however, produce an unacceptably high total dose of medication. Finally, we found that only two trainees knew of the existence of a policy for $\mathrm{RT}$ in their workplace.

This study has methodological flaws, given that it was retrospective and reliant on memory. However, it is likely that respondents documented their 'usual' $\mathrm{RT}$ regimes, revealing a wide variation in prescription habits.

Several studies in recent years have looked at RT practice, with similar results noted. Pilowsky et al (1992) found that trainees regularly exceeded BNF dose recommendations and that medication was most often prescribed parenterally. Cunnane (1994), using a vignette, surveyed consultant psychiatrists. The use of a vignette often leads to the description of the ideal, rather than the actual response to a situation. Notwithstanding the caveat, it was notable that there was evident uncertainty among consultants as to optimal management. Chlorpromazine i.m. prescribed in high dosage was the most frequent response, followed by haloperidol recommended at a far higher equivalent dosage. Most significant, perhaps, was the finding that $15 \%$ of consultant psychiatrists did not feel competent

Table 2. High-dose prescribing

\begin{tabular}{ll}
\hline Drug & No. of incidents \\
\hline Chlorpromazine $100 \mathrm{mg}$ i.m. & 4 \\
Chlorpromazine $100 \mathrm{mg}$ i.m.+benzodiazepines i.v./i.m. & 5 \\
Chlorpromazine $200 \mathrm{mg}$ i.m. & 2 \\
Chlorpromazine $200 \mathrm{mg}$ i.m.+diazepam $10 \mathrm{mg}$ i.v. & 1 \\
Chlorpromazine $200 \mathrm{mg}$ i.m.+haloperidol $20 \mathrm{mg}$ p.o. & 5 \\
Chlorpromazine $50-100 \mathrm{mg}$ i.m.+zuclopenthixol a. $100-150 \mathrm{mg}$ & 6 \\
Chlorpromazine $200 \mathrm{mg}$ i.m.+amylobarbitone sodium $200 \mathrm{mg} \mathrm{i.m.}$ & 2 \\
Droperidol $20 \mathrm{mg}$ i.m. & 1 \\
Haloperidol $15 \mathrm{mg}$ i.m.+droperidol $10 \mathrm{mg}$ i.m.+lorazepam $2 \mathrm{mg} \mathrm{i.m.}$ & 5 \\
Haloperidol $20 \mathrm{mg}$ i.m.+zuclopenthixol a. $100 \mathrm{mg}+$ lorazepam $4 \mathrm{mg} \mathrm{i.m.}$ & 6 \\
Haloperidol $20 \mathrm{mg}$ p.o.+droperidol $20 \mathrm{mg}$ i.m. & 1 \\
\hline
\end{tabular}

i.m.=intramuscularly; i.v.=intravenously; p.o.=per os (by mouth). 
to give an opinion, although participating in an emergency on-call rota. Simpson \& Anderson (1996), in a similar vignette-based study, examined RT practice in a group of senior registrars and consultant psychiatrists. They found that a majority would use a single non-depot antipsychotic, although a significant minority preferred zuclopenthixol acetate. Notably nearly $50 \%$ of respondents felt that BNF guidelines regarding maximum doses were irrelevant for RT use, thus indicating that they would exceed these in practice. Major deficiencies were evident with regard to training. Only $15 \%$ had a written policy and less than $50 \%$ were confident that junior doctors were trained in RT practice. Hillam \& Evans (1996) noted that the majority of patients in a psychiatric intensive therapy unit received antipsychotic doses which exceeded BNF maximum limits.

It appears that the practice of $\mathrm{RT}$ is consistent in its inconsistency. The Royal College published a consensus report on the use of high-dose antipsychotics in 1994. Obviously there is always a lag time between publication of a report and adoption of its recommendations; however, recent evidence suggests that these guidelines are not yet being adhered to in RT use. High-dose prescribing is very common, as is parenteral prescribing. Polypharmacy compounds the problem. Why are there ongoing problems with rapid tranquillisation? We would suggest that there are several reasons for the variation observed.

From our study it would appear that trainees have inadequate knowledge of equivalent doses of antipsychotics and the consequent risks of exceeding dose recommendations when combining drugs. Similarly, Mullen et al (1994) in a study of perception of equivalent antipsychotic dosages, found a wide variation in perceived potencies. Others (Hillam \& Evans, 1996) have commented on the disagreement regarding relative potencies of drugs and the wide variations in published tables of drug equivalents. Difficulties in converting depot medication (e.g. zuclopenthixol acetate) remain, leading to the propensity for unwittingly exceeding BNF guidelines. Furthermore, BNF guidelines regarding maximum dose limits appear inadequate. Maximum dose limits are provided for some drugs but not for others (e.g. droperidol). Similarly, no guidance is given as to maximum dosing for benzodiazepines in the emergency setting. Notwithstanding this, it has been reported that approximately half of a group of psychiatrists surveyed thought that BNF guidelines were actually irrelevant for RT use. The frequency of high-dose prescribing in most surveys would tend to confirm this. This is an important issue, implying that psychiatrists are deliberately and necessarily exceeding dose guidelines in emergency situations.
Finally, perhaps the most important issue to be addressed is the lack of training of junior doctors in this area. Simpson \& Anderson (1996) commented that senior registrars and consultants used sensible drug regimes for RT. However, this group indicated that $52 \%$ of their trainees did not receive training in $\mathrm{RT}$ procedures, thus indicating that their sensible drug regimes may not be filtering down to a more junior level.

To improve the practice of rapid tranquillisation we would call for standardised guidelines for neuroleptic equivalence to aid rational prescribing. The BNF guidelines with regard to high-dose prescribing are inadequate and regarded by some psychiatrists as irrelevant in the area of RT. These guidelines should be realistically amended to take into account the necessity for emergency tranquillisation. Finally, trainees should be made aware, through adequate training programmes and written policies, of what drugs to use in RT, what doses to employ, and how often these drugs can safely be repeated.

\section{References}

BRTTSH NATIONAL FORMULARY (1995) British National Formulary. Number 29. London: British Medical Association and Royal Pharmaceutical Society of Great Britain.

CunNane, J. G. (1994) Drug management of disturbed behaviour by psychiatrists. Psychiatric Bulletin. 18. 138-139.

DUBIN. W. R. (1989) Rapid tranquillization of the violent patient. American Joumal of Emergency Medicine, 7. 313-321.

Hillam. J. \& Evans. C. (1996) Neuroleptic drug use in psychiatric intensive therapy units: problems with complying with the consensus statement. Psychiatric Bulletin, 20, 82-84.

Mullen, R., Cann, A. W. \& Smrth. S. (1994) Perception of equivalent doses of neuroleptic drugs. Psychiatric Bulletin. 18, 335-337.

Pilowsky, L. S., Ring, H.. Shrine, P. J., et al (1992) Rapid tranquillisation, a survey of emergency prescribing in a general psychiatric hospital. Britsh Joumal of Psychiatry. 160, 831-835.

SiMPSON. D. \& ANDERSON, I. (1996) Rapid tranquillisation: a questionnaire survey of practice. Psychiatric Bulletin. 20. 149-152.

THOMPSON, C. (1994) The use of high-dose antipsychotic medication. British Journal of Psychiatry. 164. 448-458.

*Laura Mannion, Senior Registrar, Department of Psychiatry, University College Hospital, Galway, Ireland; Darina Sloan, Senior Registrar in Psychiatry, St Vincent's Hospital, Fairview, Dublin; and Louise Connolly, Registrar, Cluain Mhuire Family Centre, Blackrock, Dublin, Ireland

*Correspondence 